\title{
AN ECOCRITICAL READING OF SELECTED POEMS OF MUHAMMAD HAJI SALLEH
}

\author{
Hamoud Yahya Ahmed \\ hamoodqaleesi@yahoo.com \\ Ruzy Suliza Hashim \\ ruzy@ukm.my
}

Faculty of Social Sciences and Humanities

Universiti Kebangsaan Malaysia

\begin{abstract}
Ecocriticism is concerned with the relationship between literature and environment or how the relationships between humans and their physical world are reflected in literature. In this paper, we attempt to analyse selected poems of Muhammad Haji Salleh using some concepts from ecocriticism as an analytical lens. The premise of this paper is based on the poet's symbiotic relationship which has become a significant feature of his work. Using six of his nature poems to exhibit Muhammad's idea of mutual relationship between the human world and the natural world of environment, we show the poet's concern about the slightest interference of human beings into the world of nature which results in the disruption of human-nature relationship. Muhammad Haji Salleh does not limit himself to presenting the brighter and darker side of nature, rather he has gone a step further to reveal the very concept of ecosystem and reflect the blossoming of ecological consciousness in modern Malaysian society. This approach of reading Muhammad Haji Salleh exhibits the current interest in the environment and the ways in which it has to be treated with respect and love. By explicating the intrinsic features of nature in his selected poems, we can inculcate environmental awareness and inspire ecological consciousness among people in Malaysia and elsewhere in the world.
\end{abstract}


MALAY LITERATURE

Keywords: Ecocriticism, ecosystem, interrelationship, ecological consciousness, poetry and Muhammad Haji Salleh

\section{INTRODUCTION}

Ecocriticism is concerned with the relationship between literature and environment or how man's relationships with his physical environment are reflected in literature. It is fairly a recent phenomenon in Literature and Literary Studies. According to Johnson (2009:7-12) "over the last three decades, it has emerged as a field of literary study that addresses how human relate to nonhuman nature or environment in literature". The term ecocriticism appeared for the first time in William Rueckert's essay entitled "Literature and Ecology: An Experiment in Ecocriticism" in 1978. In this essay, Rueckert argued that literary criticism should address issues of ecology. Preceding Rueckert's essay, Josef W. Meeker's essay in 1974 entitled "The Comedy of Survival: Studies in Literary Ecology" is regarded as the very first seed in which ecocriticism was coined in literary studies. Meeker's usage of the term "literary ecology" in his essay presaged the use of ecocriticism by Rueckert in its dual meaning as the study of biological themes and relationships which appear in literary works and the attempt to discover the vital roles which have been played by both literature and the ecology of human species.

However, ecocriticism remained passive in the critical vocabulary until 1989 during which it had its revival at the Western Literature Association (WLA) meeting in Loeur d' Alene in 1989. In this meeting of WLA, two scholars, Cheryll Glotfelty, a graduate student and the assistant editor of the American Nature Writing Newspaper, and Glen Love, a professor of English at the University of Oregon, highlighted the term ecocriticism. They called for the development of such environmentally-oriented criticism and since that meeting in 1989, the term ecocriticism has bloomed (Shikha, 2011:1-2).

Ecocriticism has thus emerged as a new and growing literary field since the late 1989 and the early 1990s. More specifically, ecocriticism has evolved in North America. It entered rural universities in USA in 1980s and reached Britain in 1990s. It has become a new branch of literary criticism which examines the relations between the poet and his natural surroundings. As a father of ecocriticism, William Rueckert's first usage of the term is limited than what it has embraced nowadays. According to Rueckert, any ecological project might identify the role of nature in a poem such as the function of 
place or setting in the literary work, land metaphors as gendered entities and the environmental policies as rhetorics. This means that Rueckert's approach to ecocriticism focuses on how to use ecological principles as a model for thinking about how literature functions. According to Mwangi (2004:1-3), the western ecocriticism focused on the $19^{\text {th }}$ century poetry, which celebrated nature and wilderness. The African ecocriticism, on the other hand, was rarely practised consciously in the African Academy although the expression like "a man's struggle with the environment" is often heard in literary essays.

In Malaysian literature, ecocriticism as a tool of analysis is fairly new. The current paper is motivated by this kind of Malaysian poetry and attempts to examine to what extent ecocriticism can be used as an analytical lens for reading Malaysian poetry of nature as it has been mirrored in the Malaysian poetry of the late twentieth century particularly by Muhammad Haji Salleh, who is one of the major poets of the national literature of Malaysia.

Muhammad Haji Salleh is primarily known as a poet who utilizes the treasures of Malay culture to produce poetry which reflects his concerns about the Malay world (Raihanah M.M., 2002:51). He proves his prolificacy and versatility through his poetry. His unique treatment of nature from an aesthetic and at times ecological point of view is an aspect of this attachment to the land of his birth. Among his well-known poems of nature are these selected poems discussed in this article, namely, "the Forest's Last Day", "the Seeds", "Rain", "Night Rain", Leaf Fall" and "the Tree" (Muhammad Haji Salleh 2000: 42,49,186,187,188 and 200). These poems have been selected from Muhammad Haji Salleh's book Rowing Down Two Rivers, a collection of 148 poems. In the selected corpus which emphasise on nature and the natural environment, Muhammad Haji Salleh pays great attention to the idea of the mutual relationships between human beings and the world of nature which is central to the field of ecocriticism.

\section{REFLECTION OF NATURE IN MUHAMMAD HAJI SALLEH'S POETRY}

Nature has been one of the often treated themes in literature especially in poetry composed in any language all over the world. It has proved to be a formative strategy of sensitizing the poets' feelings and minds. As Shende (2012:22) emphasizes, the creative, destructive, healing and smoothing dimensions of nature are explicitly brought out by different poets to highlight different aspects of their views of the world and its people. 
According to Maharam Mamat et al. (2011:118), "the ecocriticism movement in Malaysia is still new and not mentioned or discussed by any literature association". They also attempt to use ecocriticism as an approach to study the two environmental issues addressed by Sarawak writers. They argue that novels that are produced by Sarawak writers are rich in features, elements, and issues related to environment. Using ecocriticism, their study covers two main environmental issues: the impact of land use on the environment and degradation of environmental quality as a result of pollution. Similarly, in this paper, we pursue the same trajectory which relates to nature and how its properties are being cared for or degraded by human beings.

There is not a particular Malaysian poet who can be identified as an enthusiastic disciple of nature. However, some of them do write and celebrate nature in their works, namely, Ee Tiang Hong and Muhammad Haji Salleh. In a country blessed with an exceptionally green land and beautiful landscape like Malaysia, nature without doubt inspires the poets to write about it and celebrate its beauty and values. This is because their poems are the result of their experience and relationship with nature.

Furthermore, it is clear, that sometimes, to describe something indirectly through nature is a preferred mode of expression, than through other nonanimate metaphors. As a poet, Muhammad Haji Salleh has been highly influenced by the unique nature of his home country and its beauty. To him, everything is poetic including all the aspects of the Malaysian nature. This is echoed in his introduction to Rowing Down Two Rivers from which the poems of this paper have been selected when he remarks (2000:14) that:

As a poet, all things are "poetic" to me, all are legitimate themes for wonderfully flexible verse form. Things and events that I live with and experience, which touch me visually or emotionally, light up certain frames of experience, insight or meaning, they are recreated as the centre of these poems.

Regarding his approach and appreciation of nature in his poems, he asserts in the same introduction (2000:12) that he draws his creativity from the remarkable collective genius and language, replete with images of nature that reach out to the coals and seas, from the mountains and the valleys, with the birds of the land. He continues to say "most of all I owe my poems to the broad and the varied lives lived in the places I have visited or stayed in" (2000:12). Thus, it can be logically assumed that most of his poems are 
written based on his personal feelings towards nature in Malaysia as well as the other places he has been in various sojourns.

In the poetry of Muhammad Haji Salleh, nature is one of the most recurrent themes and it seems to be a formative aspect of his poetry. For instance, as can be observed in his collection of poems Rowing Down Two Rivers (2000), he writes on flowers, seeds, trees, red sea, vegetables, rain, leaf fall, forests and others. This means that he has been highly captivated by the vitality of nature and therefore, he addresses its various aspects to reflect his worldviews (Muhammad Haji Salleh, 2000:5-10).

\section{A BRIEF REVIEW OF MUHAMMAD HAJI SALLEH'S VIEW OF NATURE}

Reading poems of Muhammad Haji Salleh reveals a repeated reference to the world of nature in which the various aspects of nature are fully connected to the human world. The selected poems of this paper are fine illustrations in which we can trace the kind of relationship the poet has developed between the world of human beings and the world of nature. References to the various phenomenon of nature abound in his poetry such as flowers, birds, Malaysian trees, animals and leaves. They convey insightful facets of human interaction with their habitat.

In the first selected poem "the Forest's Last Day", he presents nature with its minute details by depicting the various elements of the forest such the different Malaysian trees of cengal, meranti, merbau, pulai, seraya, nyatuh, resak, halban, nibung and rattan. Death gives opportunity to barbarism to uncover itself when the world of nature is numb to fight against its destructor. Then morning comes, with promising propaganda of the falling of flowers. The moon melts and falls and grass will make the world green one more time; birds will sing and happiness appears in the nature. Brightness prevails. It is time to grow, to reproduce, and change the world of the forest. The poem ends with such a tragic astounding image of "the red desiccated desert".

In other selected poems, Muhammad Haji Salleh presents the dependence of man on nature for survival. Apart from that, these poems highlight the value of nature to human beings; they highlight the power of nature as a source of living and as supporter of the world of human beings. Therefore, these poems echo of ecocriticism. Indeed, in these poems, he establishes a new way of looking at the natural environment. Through them, Muhammad Haji Salleh sees Malaysian nature through new eyes and rebuilds nature's role 
in human life. He also describes the interrelationship between humans and nature. He reminds of the need for humans and nature to co-exist peacefully. Above all, nature gives mankind the potential to do anything in his point of view. These ideas form the quintessence of ecological balance. Ecocriticism suggests the same ideas are imbibed by Muhammad Haji Salleh even before the term ecocriticism became fashionable in the Western context.

Furthermore, on the one hand, it seems that nature, for him, is an ultimate source of inspiration for humans. It serves as the key provider in the welfare of people and the sole source of man's well-being. Nature looks beautiful and valuable because of how people perceive it and it links the human world and the natural world. This view of nature in his poems reflects, to a large extent, the opinion of an environmentalist who artistically places emphasis on the vital and constant relationship between the humans and the natural environment surrounding them and their mutual and close dependency on each other.

On the other hand, Muhammad Haji Salleh has proved that the slightest interference of human beings into the world of nature results into much disruption of the relationship that humans try to establish with the sphere of nature. The continuous tendency of human beings to log trees in the Malaysian forests is a fine example provided by Muhammad Haji Salleh in his poem "the Forest's Last Day" as can be seen in the concluding lines of the poem when he depicts:

And a bloated logger

Who stands on the red desiccated desert-

The world of future

Indeed, Muhammad Haji Salleh attempts, on the one hand, to establish a bond of affection and benevolence and a vital interrelationship between human world and the world of nature as can be understood from the two selected poems "Rain" and "Seeds". On the other hand, he sheds light, as can be traced in "the Forest's Last Day", on the cruel interference made by humans to defile the relationship with the world of nature.

\section{ECOCRITICISM}

Ecocriticism as a literary theory is really quite young. It has been developing rapidly since the 1990s, focusing mainly on the study of the relationship between humans and the natural world. It has evolved out of many traditional 
approaches to literature and it is interdisciplinary in nature. The literary works are viewed in terms of place or the environment (Johnson, 2009:7).

The concept of ecocriticism, which was coined by William Rueckert and disseminated by critics such as Glen Love, Cheryll Glotfelty and Harold Fromm, has invoked other critics such as Grey Garrard to shed light on a number of key concepts of ecocriticism. For instance, Garrard's accessible volume (2004) traced many notions that have most occupied the ecocritics' minds. These ideas include pollution, position, pastoral, apocalypse, wilderness, and dwelling (Garrard, 2004). However, the concepts used in this study have been adapted from other fields such as ecology and eco-philosophy, which are directly linked to literature under the umbrella term of ecocriticism. These concepts are ecosystem, interrelationship and ecological consciousness.

\section{THE CONCEPT OF ECOSYSTEM}

An ecosystem is a concept with a specific and recognizable landscape such as the forest, desert, wetland or coastal area. The nature of the ecosystem is based on its geographical features like hills, mountains, plains, rivers and islands. The living part of the ecosystem is referred to as its biotic components. The living community of plants and animals in any area together with the non-components of the environment such as soil, air and water constitute the ecosystem (Gadge, 2012:41).

The aspects of ecosystem interact with each other through several functional aspects to form nature's ecosystems. All the chains of ecosystem are joined together to form the "web of life" on which we, humans depend for our continual existence. In this context, the concept of ecosystem has been adapted in this framework for the purpose of examining to what extent it is reflected in the selected poems and find out how these ecosystems are manifested in them to exhibit the interrelationship between the human world and the realm of natural environment.

\section{INTERRELATIONSHIP}

Interrelationship is among the most basic of ecocriticism tenets as ecocriticism takes as its subject the interrelationship between humans and nature. Glotfelty (1996:105) presents a definition of ecocriticism that "takes as its subject the interconnections between nature and culture". Therefore, this concept involves analyzing the interplay between humans and their environment and 
the relationships that exist between them in the literary texts. Branch (1993:20) argues that if we are biologically and psychologically defined by our natural interrelationships, then value must reside in the integrity of our natural world. Within the context of this study, this concept of interrelationship will be used to analyze the kind of relationships Muhammad Haji Salleh makes between his world and the domain of nature in the selected poems.

\section{ECOLOGICAL CONSCIOUSNESS}

Ecological consciousness is a concept emerging from current environmental studies and the most abstract of the basic ecophilosophical ideas. Broadly speaking, ecological consciousness is the change in attitude or belief which must precipitate and co-opt any significant ecophilosophical revision of the human relationship to non-human world. While ecological awareness reflects the attention we give to patterns of natural interrelationship, and ecological conscience conveys our sense of obligation to protect these patterns from excessive disruption, ecological consciousness refers more directly to our personal feelings of membership in the natural communities such patterns describe (Branch, 1993:31).

This concept termed as ecological consciousness is included as part of the framework that will be utilized for the analysis. Within the context of this paper, ecological consciousness will be appropriated to show how Muhammad Haji Salleh helps promulgate the ecological ethos which is an important aspect of his poetry and whose legacy is increasingly apparent in Malaysian natural values today.

These three concepts will be used in this framework to analyze the corpus which has been chosen carefully to match the core idea of this paper. They project natural objects as their focus and they show how the poet has viewed nature from an ecological perspective. Moreover, the choice of such poems is based on an exceptional close relationship between the human world and the realm of nature and how they interact with each other which is central to the field of ecocriticism.

\section{THE CONCEPT OF ECOSYSTEM IN MUHAMMAD HAJI SALLEH'S POEMS}

Ecosystems are the basis of life itself. The natural ecosystems provide a variety of products and are regions in which a number of vital ecological 
processes reside; without these processes human civilization would not be able to exist. However, ecosystems are highly sensitive and frequently disrupted by human misdeeds and ill-treatment of the natural world, leading to extinction of species of plants and animals whose ecosystems have been compromised.

This idea of disruption of ecosystem by human actions forms the thrust in "The Forest's Last Day" when the poet writes in the opening lines of the poem:

Death comes at the end of the chain saw

With spears of shriek that split the air and red of the sun

Biting into the flesh of wood

These words reveal the cruelty of humans towards the world of nature using their machinery to destroy the forest. The sense of human cruelty and their tendency to defile nature is evoked from the image "biting into the flesh of wood". He contrasts the annihilation of nature to a time when the ecosystem of the environment is in harmony with other beings:

In its canopy birds still play

Its air made fragrant by the essence of the forest

The sky is the witness with clear eyes

These lines reflect the ecosystem of the world natural environment and how the living beings interact with each other in a sustainable manner. The birds still play, the air made fragrant of the forest and the sky is looking upon them in the best of the comportment and the whole image shows nature at its best and in synchrony.

Likewise, the poet unearths the idea of ecosystem in the poem "Leaf Fall" when he notes:

Branches crowd

The narrow dry sky

Brushes held by the painter's nicotine fingers

Reaching to craft the monotonous glare of the blue

Leaves fall

Latex rushes to the buds

Life returns with the rain. 
In these lines, Muhammad Haji Salleh exhibits the harmony of the whole natural ecosystem and how the various elements of nature incorporate with each other to maintain healthy and wealthy life among them. This kind of harmony becomes obvious in the last three lines when he uses the images of "leaves fall", "latex rushes to the buds" and "life returns with the rain" which make the whole harmonious ecosystem of nature overt.

In contrast, the stanza below depicts the interference of humans and how they tend to spoil the harmony between them and the natural world surrounding them.
Fallen is the cengal
Fallen is the meranti
Fallen is the merbau
Fallen is the pulai
Fallen is seraya
Fallen is the resak
Fallen is the balban
Fallen is the nibung
Fallen is the rattan

By using Malay terms to identify Malaysian trees, Muhammad Haji Salleh reminds us of the uniqueness of our forest and how these trees fall victims to human tyranny and destruction. Consequently, the whole ecosystems of the natural world in these forests are disturbed by human actions as can be traced in the following lines:

The frame of balance is broken, since trees became earth The quiet beauty filtered by the light fades out

Leaves are dumb, branches speechless, no song, and no echo

No deer, no baboon, no elephant herd

No pulse of mouse deer's bleat, no question

The poet artistically reveals that many creatures which thrive within the forest will be irretrievably damaged because their lives depend on the equilibrium of the ecosystem:

The full epic of the forest

Is ended by a convoy of Lorries with tyres of concrete,

A gang of paid lumberjacks who wear no pity in their eyes 
Here he presents a clear picture of human insensitivity towards the world of nature. This implies that the interaction between human world and the sphere of nature has been spoiled due to greed and ill-managed industrialization. The image of humans being as hostile destructors of the elements of the ecosystem of the two worlds of human and non-human will eventually ravage the environment.

\section{INTERRELATIONSHIP BETWEEN HUMAN WORLD AND THE NATURAL WORLD}

Among the most basic of ecocriticism tenets is the concept of interrelationship. This is because the focal point of ecocriticism is the interrelationship between human world and the natural world. Glotfelty (1996:105) presents a definition of ecocriticism that "takes as its subject the interconnections between nature and culture". Therefore, this concept involves analyzing the interplay between humans and their environment and the relationships that exist between them and the degree to which it can be echoed in the literary work. In this vein, Muhammad Haji Salleh's poems do reflect this kind of interrelationship between the human world and the sphere of nature which is central to the field of ecocriticism. This interrelationship can be traced in the selected poems of this paper as in the poem "Seeds" when he asserts:

These seeds in the hope-bowel of my palms

I wet with water of the new season.

In my grasp I feel their skins burst and slap my hands

Yellow shoots creeping into my blood

Now as I drop them into

Morning earth, they are plants within me,

Growing on my blood and my sweat-belt

Indeed, Muhammad Haji Salleh artistically establishes a clear and deep interrelationship between the human world which he represents and the natural world symbolized by the seeds by using images of "yellow shoots creeping into my blood" and "they are plants within me". The poet goes a step further in depicting the depth of that kind of interplay when he claims that such plants have become a part of him-his identity is linked to the seeds that are growing in his blood and body.

His interrelationship with the world of nature, as a representative of the relationship between the two spheres of humans and non-human, has 
transcended the limits the physical environment and has become emotional as can be seen in the following lines:

Fall in love with the seasons

Evenings and mornings

Nurture me

Penetrate my fruits

And return me to my new blood.

These lines reflect the keenness of the poet's ecological predisposition in depicting the interrelationship and dependence of human and nature. He savours the sensuous delight of nature when he declares that he is in love with "seasons" and the evenings and mornings take care of him and provide him a new life symbolized by "new blood". Indeed, all the images used by Muhammad Haji Salleh in this short but rich poem are suggestive and reflective of the symbiotic interrelationship between his world and the realm of nature.

This kind of developed interrelationship between humans and natural world in Muhammad Haji Salleh's perspective is laden with meaning in the "Night Rain" when he says:

And now as you span your hands

Stretching the new edges of the day

Brittle drops break

On your palms

Communicating you

With the rain that brought yourself

Back from where you were.

In these lines the poet tactfully and subtly exposes a kind of communicative relationship between humans and nature in the form of such brittle drops breaking on human palms at night. The open palms remind us of a man's prayer as he holds up in hands in supplication; here, Muhammad Haji Salleh adds poignancy to his relationship with nature because it reminds him of his Maker.

In the poem "Rain", the poet emphasizes that humans are found at their best when they live close to the world of nature. He defines the essence of the interrelationship with nature in the following lines: 
Water is here

In season

In earth

In man

The word "water" stands for the whole picture of the interrelationship as it is the essence of life in human and non-human world, and this image of "water is here" symbolizes the chain of relationship that binds all elements of these two domains. Indeed, the ordinary things of life and nature assume a new appearance and acquire a new meaning through the poet's ecocritical slant. By doing so, Muhammad Haji Salleh has triggered ecological consciousness in the Malaysian context which we will discuss in the following section.

\section{ECOLOGICAL CONSCIOUSNESS}

Ecological Consciousness seems to be the mainstream in Muhammad Haji Salleh's poems in general and in the six selected poems, in particular. In his poems, nature has acquired ecological significance as well. In a developed country like Malaysia, technology and the growth of the modern city life have divorced Malaysian people from its unique and lush nature. Therefore, Muhammad Haji Salleh's poems re-establish vital contact of the locals with the world of nature. We cannot actually reside in the woods in this technological era but we should try to be in the company of nature which has healing effects.

In the poem "Forest's Last Day", the poet establishes a strong sense of ecological consciousness towards the current trends of destroying the Malaysian forests and replacing them with modern cities and industries. $\mathrm{He}$ depicts that kind of practice towards the natural world when he declares:

The full epic of the forest

Is ended by a convoy of lorries with tyres of concrete,

A gang of paid lumberjacks who wear no pity in their eyes.

In these lines, the poet reveals the current inconsiderateness of Malaysian people who have become materialistic in the era of technology and their tendency to destroy the natural world. The image of "a gang of paid lumberjacks who wear no pity in their eyes" is a humanistic cry of the poet against the modern ways of annihilating the forests and other aspects of natural world. 
The poem ends with a very suggestive image of constructing ecological consciousness among people in the present era. The poet implicitly depicts the future of Malaysia and the world as being insensitive to the ecological values of the natural world when he writes:
And a bloated logger
Who stands on the red desiccated desert
The world of future

The image of "the red desiccated desert" reveals Muhammad Haji Salleh's sense of ecological consciousness and serves as a environmental cry and an ecological calling for being aware of the recent phenomenon of desecrating the forests and natural areas and replacing them by cities and factories in Malaysia and elsewhere in the world. The poet depicts the forest as being preyed by greedy people as represented by a "bloated logger". The ecological implications are echoed in the poet's awareness of the great loss of luxuriant greenery to be replaced by dried out earth and shrunken trees.

In the poem "Seeds", the poet's ecological consciousness becomes more overt when he says:
I flow with the youth of my blood,
Fall in love with the seasons
Evenings and mornings
Nurture me
Penetrate my fruits
And return me to my new blood

These lines reveal the poet's ecological consciousness. He has shared a close relationship and love in the world of nature and its various forms are looking after him, provide him with intangible values, and even make him aware of the regeneration of life. Indeed, Muhammad Haji Salleh's ecological consciousness arises out of his true awareness of the recent environmental crisis sweeping the entire world. This poem reminds us of our need to be close to nature to which we, humans, are related as if it were in a blood-relationship.

In the poem "Rain", Muhammad Haji Salleh has implicitly expressed his intense sense of ecological consciousness when he describes the rain that nurtures padi to thrive: 
It is the beginning of a gift

Usin's muscles quiver

As leaves and young coconuts

The water washes death off

Dust and drain

The poem in general and the lines above reveal the poet's philosophy of existence drawn from nature. His attentiveness seems to possess two aspects. Firstly, he is conscious of the external values as represented by the blessed rain that is important for growing padi. Secondly, he is aware of the environmental danger to nature in the era of industrialization and pollution which are symbolized by the "dust and drains". Therefore, the poet reminds us of the therapeutic and healing properties of water and how it regenerates and nurtures life.

Above more, the representation of ecological consciousness through the poetry of Muhammad Haji Salleh has transcended all limits of space and time. This can be proved by his poem "the Tree" in which he asserts:

Tomorrow, I shall see you

As you wish to show yourself

Green and arranged.

Indeed, his address to the tree "I shall see you" is an ecological call to his Malaysian nation to be ecological conscious towards the land that gives so much back in return. Accordingly, Muhammad Haji Salleh's poetry can be used to instill environmental awareness and inspire ecological consciousness among Malaysian modern society.

To conclude, Muhammad Haji Salleh's poems provide one of the best examples through which we can imbue environmental awareness and inspire ecological consciousness among people. He has succeeded in highlighting the visible and invisible relationship between human world and the world natural environment. Indeed, he has a direct appeal to the core of the field of ecocriticism.

\section{CONCLUSION}

In this paper, we have attempted to analyse the ecocritical insights in the poetry of Muhammad Haji Salleh, by specifically engaging some selected poems rooted in nature and the natural environment of Malaysia. Indeed, as 
we have shown, he has focused on his idea of mutual relationship between people and nature, and the close relationship both share for harmonious coexistence. As a consequence of this interrelationship, he has exhibited that the slightest interference of human beings into the world of nature results in disruption of that relationship. Unlike many major poets, Muhammad Haji Salleh does not limit himself to presenting the brighter and darker side of nature; rather he has gone a step further to reveal the very concept of ecosystem and raises the idea of the recent ecological consciousness in the modern society.

The implication of this paper is that the field of ecocriticism can be used as a useful analytical lens for reading the poetry of Muhammad Haji Salleh. Furthermore, his poems can be used as an ecological discipline through which we can instill environmental awareness and inspire ecological consciousness. Undeniably, ecocriticism opens up new vistas of reading Muhammad Haji Salleh's use of nature, extending what we know of his connection between land and identity-an important facet of his works, to fresh appreciation of Malaysia's unique fauna and flora, richly described in his poetry, to highlight the overt and covert relationship between the human world and the natural environment that needs to be kept in equilibrium.

\section{REFERENCES}

Gadge Narendra, "Ecology and Ecocriticism" in Journal of Science Information special Issue, 3, pp. 41-49, 2012.

Glotfelty \& Fromm, 1996. The Ecocriticism Reader: Landmarks in Literary Ecology. Athens: University of Georgia Press.

Greg Garrard, 2004. Ecocriticism. New York: Routledge.

Johnson L., 2009. "Greening the Library: The Fundamentals and Future of Ecocriticism" in http://www.asle.org/assets/docs/Ecocriticism_ essay. Retrieved 31 March 2012.

Maharam Mamat, Johari Talib and Zulkifli Mohammad, "Environmental Issues in Literary Works in Malaysia: Preliminary Study of Sarawak Novel Writers" in World Review of Business Research 1:4, pp. 11534, 2011.

Michael Branch, 1993. "The Enlightened Naturalist: Ecological Romanticism in American Literature”. Unpublished Ph.D. Thesis. University of Virginia. 
Muhammad Haji Salleh, 2000. Rowing Down Two Rivers. Bangi: Penerbit UKM.

Mwangi, E. (2004). "A Shot in the Arm for African Ecocriticism" in http:// www.asle.org/site/resources/ecocritical-library/intro/nobel/. Retrieved 31 March 2012.

Raihanah M.M, "Malaysia and the Author: Face- to Face with the Challenges of Multiculturalism" in IJAPS 5:2, pp. 43-63, 2009.

Sanjay Shende, 2012. "Eco-critical Perspective on Emily Dickinson's Poems" in Journal of Science Information Special Issue, 3, pp. 22-29.

Shikha, Kumari, "Ecocriticism in Indian Fiction" in IRWLE 7:1, pp. 1-12, 2011. 